\title{
Supervised physiotherapy for mild or moderate ankle sprain
}

\author{
(@) $(1) \Theta$ OPEN ACCESS \\ Clinical benefit might depend on the nature, intensity, and duration of treatment
}

\section{Chris Bleakley lecturer}

Ulster University, Faculty of Life and Health Sciences, Newtownabbey,BT370QB, UK

Lateral ankle sprains are the most common musculoskeletal injuries in physically active populations. ${ }^{1}$ Incidence rates in the general population are also high, at an estimated five to seven injuries per 1000 people per year. ${ }^{23}$ More than $40 \%$ of patients fail to recover because of persistent pain, recurrent injury, and instability. ${ }^{4}$ These symptoms, which are characteristic of chronic ankle instability, result in long term constraints to levels of physical activity and could be a key mediator for post-traumatic osteoarthritis. ${ }^{4}$ Despite this, many patients regard ankle sprains as being innocuous with fewer than half seeking formal medical care. ${ }^{5}$ This generally occurs in an emergency care facility and is based on advice for self management. While supervised rehabilitation represents a more comprehensive approach, there is ongoing controversy around its cost benefit ratio.

The randomised controlled study by Brison and colleagues (doi:10.1136/bmj.i5650) is one of the largest to assess the therapeutic benefits of supervised physiotherapy after acute ankle sprain. ${ }^{6}$ The authors recruited 503 patients, aged 16-79, presenting with mild or moderate ankle sprains to two acute care settings in Canada. Participants were randomised to receive usual care (based on protection, rest, ice, compression, and elevation) or usual care plus a regimen of supervised rehabilitation. Ankle function reported by patients, re-injury, clinical measures, and laboratory based assessments of ankle strength were recorded at one, three, and six months.

Stratification was used to ensure that baseline function was similar across each of the intervention groups, and retention was $80 \%$ at the six month follow-up.

The findings showed few differences between groups, suggesting that the addition of supervised rehabilitation to usual care results in little clinical benefit. This conflicts with the current evidence base. In a recent meta-analysis, ${ }^{7}$ pooled data from 23 randomised controlled studies involving participants with a history of ankle sprains found that rehabilitative exercises were associated with significant improvements in self reported function and reduced risk of recurrent injury (odds ratio $0.57,95 \%$ confidence interval $0.49,0.66)$. Sensitivity analyses suggested that the risk of recurrent injury was lowest in studies that used a higher cumulative duration of therapeutic exercise (more than 900 minutes) $(0.48,0.37$ to 0.63$)$. Brison and colleagues ${ }^{6}$ used a maximum of seven lots of 30 minutes of supervised exercise interventions (total 210 minutes), which, though supplemented by a home based exercise regimen, might be a "lower dose" than other studies.

Patients and practitioners should also consider that many other exercise dose parameters can influence treatment success. Manipulating the magnitude, nature, intensity, and frequency of exercise can have profound effects on the structure and function of the neuromusculoskeletal system. ${ }^{8}$ Important details of these parameters, however, are often missing from trials of exercise treatments for ankle sprain (including this one), ${ }^{67}$ making it difficult for readers to judge the clinical appropriateness of trial interventions. A related limitation is that most exercise interventions for lateral ankle sprain tend to focus entirely on the ankle joint. ${ }^{7}$ But there is increasing evidence that these sprains also affect movement patterns in joints proximal to the ankle, such as the knee, hip, and in the torso. ${ }^{9}$ As many of these movement deficits are thought to be implicated in the development of long term problems such as chronic ankle instability, there is an urgent need for practitioners and researchers to diversify the exercise content of treatments beyond the ankle.

An interesting finding was that just under 60\% (299/503) of participants reported a previous injury to their ankle at the start of the study. This further highlights the propensity for poor recovery after a lateral ankle sprain and the high rate of recurrence. Recurrent injury is a characteristic symptom of chronic ankle instability, a potentially important variable moderating the effectiveness of therapeutic exercise. Only a small number of studies ${ }^{7}$ have successfully controlled for any confounding effects of chronic instability by limiting recruitment to participants with a first ankle sprain. Future researchers might usefully prioritise this element of trial design.

This new randomised study is an important addition to the evidence base. ${ }^{6}$ Strengths include a robust design incorporating 
adequate randomisation, allocation concealment, and blinded assessment of outcomes. Future research, however, must do more to identify the optimal dose and intensity of therapeutic exercise in the management of mild or moderate lateral ankle sprain. $^{10}$

Competing interests: I have read and understood the BMJ Group policy on declaration of interests and declare the following interests: None.

Provenance and peer review: Commissioned; not peer reviewed.

1 Waterman BR, Owens BD, Davey S, Zacchilli MA, Belmont PJ Jr. The epidemiology of ankle sprains in the United States. J Bone Joint Surg Am 2010;92:2279-84. doi:10.2106/ JBJS.I.01537 pmid:20926721.

2 Hølmer P, Søndergaard L, Konradsen L, Nielsen PT, Jørgensen LN. Epidemiology of sprains in the lateral ankle and foot. Foot Ankle Int 1994;15:72-4. doi:10.1177। 107110079401500204 pmid:7981804.

3 Bridgman SA, Clement D, Downing A, Walley G, Phair I, Maffulli N. Population based epidemiology of ankle sprains attending accident and emergency units in the West Midlands of England, and a survey of UK practice for severe ankle sprains. Emerg Med J 2003;20:508-10. doi:10.1136/emj.20.6.508 pmid:14623833.

4 Gribble PA, Bleakley CM, Caulfield BM, et al. Evidence review for the 2016 International Ankle Consortium consensus statement on the prevalence, impact and long-term consequences of lateral ankle sprains. Br J Sports Med 2016bjsports-2016-096189. doi: 10.1136/bjsports-2016-096189. pmid:27259753.
5 McKay GD, Goldie PA, Payne WR, Oakes BW. Ankle injuries in basketball: injury rate and risk factors. Br J Sports Med 2001;35:103-8. doi:10.1136/bjsm.35.2.103 pmid: 11273971.

6 Brison RJ, Day AG, Pelland L, et al. Effect of early supervised physiotherapy on recovery from acute ankle sprain: randomised controlled trial. BMJ 2016;355:i5650.

7 Doherty C, Bleakley C, Delahunt E, Holden S. Treatment and prevention of acute and recurrent ankle sprain: an overview of systematic reviews with meta-analysis. $\mathrm{Br} J$ Sports Med 2016doi:10.1136/bjsports-2016-096178.

8 Glasgow P, Phillips N, Bleakley C. Optimal loading: key variables and mechanisms. Br J Sports Med 2015;49:278-9. doi:10.1136/bjsports-2014-094443 pmid:25950028.

9 Doherty C, Bleakley C, Hertel J, Caulfield B, Ryan J, Delahunt E. Recovery From a First-Time Lateral Ankle Sprain and the Predictors of Chronic Ankle Instability: A Prospective Cohort Analysis. Am J Sports Med 2016;44:995-1003. doi:10.1177/ 0363546516628870 pmid:26912285.

10 van Dijk CN, Vuurberg G. There is no such thing as a simple ankle sprain: clinical commentary on the 2016 International Ankle Consortium position statement. Br J Sports Med 2016;bjsports-2016-096733. doi:10.1136/bjsports-2016-096733. pmid:27797735.

Published by the BMJ Publishing Group Limited. For permission to use (where not already granted under a licence) please go to http://group.bmj.com/group/rights-licensing/ permissions

This is an Open Access article distributed in accordance with the Creative Commons Attribution Non Commercial (CC BY-NC 3.0) license, which permits others to distribute, remix, adapt, build upon this work non-commercially, and license their derivative works on different terms, provided the original work is properly cited and the use is non-commercial. See: http://creativecommons.org/licenses/by-nc/3.0/. 